Pacific Journal of Mathematic 


\title{
A SELECTION THEOREM FOR GROUP ACTIONS
}

\author{
JOHN P. BURGESS
}

\begin{abstract}
Let a Polish group $G$ act continuously on a Polish space $X$, inducing an equivalence relation $E$. Let $E_{Y}$ be the restriction of $E$ to an invariant Borel subset $Y$ of $X$. Assume $E_{Y}$ is countably separated. Then it has a Borel transversal.
\end{abstract}

Throughout, let $\Gamma$ be a continuous action of a Polish group $G$ on a Polish space $X$. Thus $X$ is a separable space admitting a complete metric, while $G$ is a topological group whose topology is separable and admits a complete metric, and $\Gamma$ is a continuous function $G \times X \rightarrow X$ satisfying $\Gamma\left(g^{-1}, \Gamma(g, x)\right)=x$ and $\Gamma(g, \Gamma(h, x))=\Gamma(g h, x)$ for all $x \in X$ and $g, h \in G$. We write $g x$ for $\Gamma(g, x)$, and for subsets of $X$ write $g A$ for $\{g x: x \in A\} . \quad \Gamma$ induces an equivalence relation $E$ on $X: x E y$ iff $g x=y$ for some $g \in G$. $W \subset X$ is invariant if $g W=W$ for all $g \in G$. Let $Y \subset X$ be an invariant Borel set, $E_{Y}$ the restriction of $E$ to $Y$. A transversal or selector-set for an equivalence relation is a set composed of exactly one representative from each equivalence class. Let us assume $E_{Y}$ is countably separated, i.e., that there exist invariant Borel $Z_{0}, Z_{1}, Z_{2}, \cdots \subset Y$ such that for all $x, y \in Y$ :

$$
x E y \longleftrightarrow \forall m\left(x \in Z_{m} \longleftrightarrow y \in Z_{m}\right)
$$

our goal is to prove the following selection result:

THEOREM. Under the above hypotheses, $E_{Y}$ has a Borel transversal. It should be mentioned that a number of special cases and overlapping results have been known to and applied by $C^{*}$-algebraists for some time now. The construction of the required transversal proceeds in four stages.

Stage $A$. It will prove convenient to reserve the letters $m, n$ plain and with subscripts to range over the set $I$ of natural numbers, and to reserve $s, t$ plain and with subscripts to range over the set $Q$ of finite sequences of natural numbers. We let $s^{*} m$ denote the concatenation of $s$ and $m$, i.e., $s$ with $m$ tacked on at the end. We wish to define Borel sets $A(s)$ for overy $s \in Q$ of even length.

Case 1. $s=$ the empty sequence $\varnothing$. Set $A(\varnothing)=Y$.

Case 2. $s=a$ sequence $(m, n)$ of length two. Set $A((m, n))=Z_{m}$ 
if $n=0$, and $Y-Z_{m}$ if $n>0$.

Case 3. $s=a$ sequence of form $t^{*} m^{*} n$, where $t$ has length $\geqq 2$, and $A(t)$ is a closed set. For such $t$ we wish to define $A\left(t^{*} m^{*} n\right)$ for all $m$ and $n$ at once. In order to do so, we first fix a complete metric $\rho$ compatible with the topology of $X$. For each $m$ we then let $\left\{A\left(t^{*} m^{*} n\right): n \in I\right\}$ be a family of closed sets of $\rho$-diameter $<1 / m$ whose union is $A(t)$.

Note that in every case so far we have:

$$
A(t)=\bigcap_{m} \bigcup_{n} A\left(t^{*} m^{*} n\right) .
$$

Case 4. $s=a$ sequence of form $t^{*} m^{*} n$, where $t$ has length $\geqq 2$, and $A(t)$ is not closed. Again, for such $t$ we define all $A\left(t^{*} m^{*} n\right)$ at once.

But first we introduce by induction on countable ordinals $\alpha$ a slight modification of the usual hierarchies of Borel sets. Let $\Theta_{0}$ be the family of all closed subsets of $X$. For a countable ordinal $\alpha>0$, let $\Theta_{\alpha}$ be the family of all sets of form $\bigcap_{m} \bigcup_{n} W_{m n}$ with the $W_{m n} \in \bigcup_{\beta<\alpha} \Theta_{\beta}$. Thus $\Theta_{1}=F_{o \delta}, \Theta_{2}=F_{o \delta \delta \delta}$. For present purposes the rank of a Borel set $W$ will mean the least $\alpha$ with $W \in \Theta_{\alpha}$.

Now returning to our Borel set $A(t)$ of $\operatorname{rank} \alpha>0$, we let the $A\left(t^{*} m^{*} n\right)$ be sets of rank $<\alpha$ satisfying (1) above. This completes the opening stage of the construction.

Stage $B$. Let us fix an enumeration $s_{0}, s_{1}, s_{2}, \cdots$ of the nonempty members of $Q$, such that if $s_{m}$ is an initial segment of $s_{n}$, then $m<n$. Let $F_{n}$ denote the set of all functions $\left\{s_{0}, \cdots, s_{n-1}\right\} \rightarrow I$. (So $F_{0}$ contains only the empty function $\varnothing$.) Let $F=\bigcup_{n} F_{n}$, and let $F_{\infty}$ be the set of all functions $\left\{s_{i}: i \in I\right\} \rightarrow I$. We reserve the letters $\sigma, \tau$ plain and with subscripts to range over $F$. We say $\tau$ is an immediate proper extension of $\sigma$, and write $\sigma \subset \tau_{\alpha}$, if for some $n$, $\sigma \in F_{n}, \tau \in F_{n+1}$, and $\tau$ extends $\sigma$.

For $\psi \in F \cup F_{\infty}$ and $s=\left(m_{0}, m_{1}, \cdots, m_{k-1}\right) \in$ dom $\psi$ we define:

$\psi^{+}(s)=\left(m_{0}, n_{0}, m_{1} n_{1}, \cdots, m_{k-1}, n_{k-1}\right)$, where

$n_{0}=\psi\left(\left(m_{0}\right)\right)$ and $n_{1}=\psi\left(\left(m_{0}, m_{1}\right)\right), \cdots, n_{k-1}=\psi(s)$.

To complete stage $\mathrm{B}$ of the construction, we define $B(\sigma)$ to be the intersection of all $A\left(\sigma^{+}(s)\right)$ for $s \in$ dom $\sigma$. Unpacking all these definitions, one readily verifies that:

$$
B(\sigma)=\mathbf{U}_{\sigma \Subset:} B(\tau) .
$$

Another glance at the definitions (especially stage A, case 2) discloses:

$$
x \in B(\sigma) \&(m) \in \operatorname{dom} \sigma \longrightarrow\left(x \in Z_{m} \longleftrightarrow \sigma((m))=0\right) .
$$


Stage C. Before launching into the next stage of the construction, we define for any $W \subset X$ the Vaught transform $W^{\sharp}$ of $W$ to be $\{x \in X:\{g \in G: g x \in W\}$ is nonmeanger (2nd cafegory) in $G\}$. One readily verifies that:

$W^{\sharp}$ is invariant.

$W$ is invariant $\rightarrow W=W^{\sharp}$.

$\left(\mathbf{U}_{n} W_{n}\right)^{\#}=\mathbf{U}_{n}\left(W_{n}^{\sharp}\right)$.

It is shown in [1] that

$$
W \text { is Borel } \longrightarrow W^{\sharp} \text { is Borel }
$$

which will be all-important for us.

Now let us define $C(\sigma)=B(\sigma)^{\sharp}$. The above facts from Vaught's theory of group actions imply that each $C(\sigma)$ is an invariant Borel set, that $C(\varnothing)=Y$, and that:

$$
C(\sigma)=\mathrm{U}_{\sigma \Subset \tau} C(\tau) \text {. }
$$

Now if $x \in C(\sigma)$, then some $g x \in B(\sigma)$, so applying (3) above, and recalling that the $Z_{m}$ are invariant, we conclude:

$$
x \in C(\sigma) \&(m) \in \operatorname{dom} \sigma \longrightarrow\left(x \in Z_{m} \longleftrightarrow \sigma((m))=0\right) .
$$

Stage $D$. We say $\sigma$ lexicographically precedes $\tau$, and write $\sigma \triangleleft \tau$, if for some $n$ and $i<n$ we have $\sigma \in F_{n}, \tau \in F_{n}, \sigma\left(s_{j}\right)=\tau\left(s_{j}\right)$ for all $j<i$, and $\sigma\left(s_{i}\right)<\tau\left(s_{i}\right)$. The relation $\triangleleft$ well orders each $F_{n}$.

Let $D(\sigma)$ be the invariant Borel set $C(\sigma) \cdot \bigcup\{C(\tau): \tau \triangleleft \sigma\}$. Thus $D(\varnothing)=Y$ and by (4) and (5) we have:

$$
\begin{gathered}
D(\sigma)=\sum_{\sigma \Subset \tau} D(\tau) \\
x \in D(\sigma) \text { and }(m) \in \operatorname{dom} \sigma \longrightarrow\left(x \in Z_{m} \longleftrightarrow \sigma((m))=0\right) .
\end{gathered}
$$

In (6), $\Sigma$ denotes disjoint union.

Finally we are in a position to introduce the Borel set:

$$
T=\bigcap_{n} \bigcup_{\sigma \in F_{n}}(B(\sigma) \cap D(\sigma)) .
$$

We aim to show that $T$ is the required transversal for $E_{Y}$. To this end we consider an arbitrary $E$-equivalence class $K \subset Y$ and verify that $T \cap K$ is a singleton.

To begin with, from (6) it is evident that there exists a sequence $\varnothing=\sigma_{0} \Subset \sigma_{1} \Subset \sigma_{2} \Subset \cdots$ of e[ements of $F$ such that $K \in D\left(\sigma_{n}\right)$ for each $n$, but $K \cap D(\sigma)=\varnothing$ for any other $\sigma \in F$. Let $\psi \in F_{\infty}$ be the union of these $\sigma_{n}$.

Recall that:

$$
B\left(\sigma_{n}\right)=\bigcap\left\{A\left(\sigma_{n}^{+}\left(s_{i}\right)\right): i<n\right\}=\bigcap\left\{A\left(\psi^{+}\left(s_{i}\right)\right): i<n\right\} .
$$


Let us consider the closely related sets:

$$
L_{n}=\bigcap\left\{A\left(\psi^{+}\left(s_{i}\right)\right): i<n \text { and } A\left(\psi^{+}\left(s_{i}\right)\right) \text { is a closed set }\right\} .
$$

Manifestly the $L_{n}$ are closed and nested, $L_{n+1} \subset L_{n}$. They are also nonempty. (To see this, note that $K \subset D\left(\sigma_{n}\right) \subset C\left(\sigma_{n}\right)$ implies $K \cap$ $B\left(\sigma_{n}\right) \neq \varnothing$, and that $L_{n} \supset B\left(\sigma_{n}\right)$.) Finally, the $\rho$-diameters of the $L_{n}$ converge to zero. (To see this, consider for any given $m$ the sets $A\left(\psi^{+}((m))\right), A\left(\psi^{+}((m, m))\right), A\left(\psi^{+}((m, m, m))\right), \cdots$ By stage A, case 4 of our construction, the ranks of these sets decrease until at some step we reach a closed set; then by stage $A$, case 3 , at the very next step we get a closed set of $\rho$-diameter $<1 / m$.) Since $\rho$ is complete, $\bigcap_{n} L_{n}$ is a singleton $\{y\}$.

Claim. $y \in A\left(\psi^{+}(s)\right)$ for all $s$.

This is established by induction on the rank of the set involved: we know it already for rank 0, i.e., closed, sets. Suppose then $A\left(\psi^{+}(s)\right)$ has rank $\alpha>0$, and assume as induction hypothesis that the claim holds for sets of $\operatorname{rank}<\alpha$, e.g., for the various $A\left(\psi^{+}(s)^{*} m^{*} n\right)$. Then for any $m$, letting $n=\psi\left(s^{*} m\right)$, we have $\psi^{+}\left(s^{*} m\right)=\psi^{+}(s)^{*} m^{*} n$, and so by induction hypothesis, $y \in A\left(\psi^{+}(s)^{*} m^{*} n\right)$. This shows $y \in \bigcap_{m} \bigcup_{n} A\left(\psi^{+}(s)^{*} m^{*} n\right)=A\left(\psi^{+}(s)\right)$ as required to prove the claim.

From the claim it is immediate that $y \in \bigcap_{n} B\left(\sigma_{n}\right)$, and also that for any $m, y \in Z_{m}$ iff $\psi(m)=0$. On the other hand, by (7) above, for any $m, K \subset Z_{m}$ iff $\psi(m)=0$. But then by (0), $y \in K$. And this implies $y \in \bigcap_{n} D\left(\sigma_{n}\right)$. Putting everything together, $T \cap K=\{y\}$ as required.

\section{REFERENCES}

1. R. L. Vaught, Invariant sets in topology and logic, Fund. Math., 82 (1974), 269-293.

Received July 21, 1978. Research partially supported by NSF grant NCS 77.

PRINCETON UnIVERSITY

PRINCETON, NJ 08540 


\section{PACIFIC JOURNAL OF MATHEMATICS}

\section{EDITORS}

RICHARD ARENS (Managing Editor)

University of California

Los Angeles, CA 90024

Charles W. Curtis

University of Oregon

Eugene, OR 97403

C. C. MOORE

University of California

Berkeley, CA 94720
J. DUGUNDJI

Department of Mathematics

University of Southern California

Los Angeles, CA 90007

R. FINN and J. MILGRAM

Stanford University

Stanford, CA 94305

\section{ASSOCIATE EDITORS}

\section{E. F. BeCKENBACH}

B. H. NeumanN

F. WOLF

K. YoSHIDA

\section{SUPPORTING INSTITUTIONS}

\author{
UNIVERSITY OF SOUTHERN CALIFORNIA \\ STANFORD UNIVERSITY \\ UNIVERSITY OF HAWAII \\ UNIVERSITY OF TOKYO \\ UNIVERSITY OF UTAH \\ WASHINGTON STATE UNIVERSITY \\ UNIVERSITY OF WASHINGTON
}

The Supporting Institutions listed above contribute to the cost of publication of this Journal, but they are not owners or publishers and have no responsibility for its content or policies.

Mathematical papers intended for publication in the Pacific Journal of Mathematics should be in typed form or offset-reproduced, (not dittoed), double spaced with large margins. Please do not use built up fractions in the text of the manuscript. However, you may use them in the displayed equations. Underline Greek letters in red, German in green, and script in blue. The first paragraph or two must be capable of being used separately as a synopsis of the entire paper. Items of the bibliography should not be cited there unless absolutely necessary, in which case they must be identified by author and journal, rather than by item number. Manuscripts, in triplicate, may be sent to any one of the editors. Please classify according to the scheme of Math. Reviews, Index to Vol. 39. All other communications should be addressed to the managing editor, or Elaine Barth, University of California, Los Angeles, California, 90024.

50 reprints to each author are provided free for each article, only if page charges have been substantially paid. Additional copies may be obtained at cost in multiples of 50 .

The Pacific Journal of Mathematics is issued monthly as of January 1966. Regular subscription rate: $\$ 72.00$ a year (6 Vols., 12 issues). Special rate: $\$ 36.00$ a year to individual members of supporting institutions.

Subscriptions, orders for numbers issued in the last three calendar years, and changes of address should be sent to Pacific Journal of Mathematics, P.O. Box 969, Carmel Valley, CA 93924, U.S.A. Older back numbers obtainable from Kraus Periodicals Co., Route 100, Millwood, NY 10546.

PUBLISHED BY PACIFIC JOURNAL OF MATHEMATICS, A NON-PROFIT CORPORATION

Printed at Kokusai Bunken Insatsusha (International Academic Printing Co., Ltd.). 8-8, 3-chome, Takadanobaba, Shinjuku-ku, Tokyo 160, Japan. 


\section{Pacific Journal of Mathematics}

\section{Vol. 80, No. $2 \quad$ October, 1979}

K. Adachi, On the multiplicative Cousin problems for $N^{p}(D) \ldots \ldots \ldots \ldots 297$

Howard Banilower, Isomorphisms and simultaneous extensions in $C(S) \ldots 305$

B. R. Bhonsle and R. A. Prabhu, An inversion formula for a distributional

finite-Hankel-Laplace transformation ................... 313

Douglas S. Bridges, Connectivity properties of metric spaces.......... 325

John Patton Burgess, A selection theorem for group actions ........... 333

Carl Claudius Cowen, Commutants and the operator equations

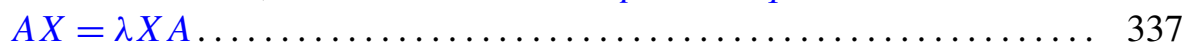

Thomas Curtis Craven, Characterizing reduced Witt rings. II .......... 341

J. Csima, Embedding partial idempotent d-ary quasigroups ............ 351

Sheldon Davis, A cushioning-type weak covering property ............ 359

Micheal Neal Dyer, Nonminimal roots in homotopy trees ............. 371

John Erik Fornaess, Plurisubharmonic defining functions ........... 381

John Fuelberth and James J. Kuzmanovich, On the structure of finitely

generated splitting rings .......................... 389

Irving Leonard Glicksberg, Boundary continuity of some holomorphic

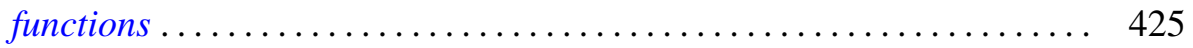

Frank Harary and Robert William Robinson, Generalized Ramsey theory.

IX. Isomorphic factorizations. IV. Isomorphic Ramsey numbers .......

Frank Harary and Allen John Carl Schwenk, The spectral approach to determining the number of walks in a graph...........

David Kent Harrison, Double coset and orbit spaces ..... . .

Shiro Ishikawa, Common fixed points and iteration of commuting

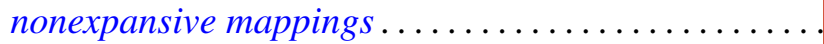

Philip G. Laird, On characterizations of exponential polynomials ........ 503

Y. C. Lee, A Witt's theorem for unimodular lattices ...........

Teck Cheong Lim, On common fixed point sets of commutative

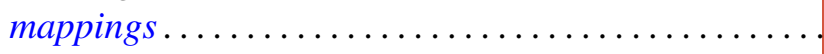

R. S. Pathak, On the Meijer transform of generalized functions ...

T. S. Ravisankar and U. S. Shukla, Structure of $\Gamma$-rings . . .

Olaf von Grudzinski, Examples of solvable and nonsolvable convolution

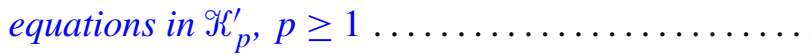

